\title{
Monitoring of Lung Involvement in Rheumatologic Disease
}

\author{
Koralia E. Paschalaki ${ }^{a, c}$ Joseph Jacob ${ }^{b}$ Athol U. Wells ${ }^{c}$ \\ ${ }^{a}$ Airway Disease Section, National Heart and Lung Institute, Imperial College London, and ${ }^{\mathrm{b}}$ Department of \\ Radiology and ${ }^{\mathrm{C} I n t e r s t i t i a l ~ L u n g ~ D i s e a s e ~ U n i t, ~ R o y a l ~ B r o m p t o n ~ H o s p i t a l, ~ L o n d o n, ~ U K ~}$
}

\section{Key Words}

Monitoring $\cdot$ Connective tissue disease $\cdot$ Symptomatic change - Pulmonary function tests . Chest radiography . Pulmonary hypertension

\begin{abstract}
The monitoring of lung involvement in patients with connective tissue diseases is central to optimal long-term management and is directed towards: (a) the detection of supervening lung involvement not present at presentation and (b) the identification of disease progression in established lung disease. For both goals, accurate surveillance requires multidisciplinary evaluation with the integration of symptomatic change, serial pulmonary function trends and imaging data. Evaluated in isolation, each of these monitoring domains has significant limitations. Symptomatic change may be confounded by a wide variety of systemic factors. Pulmonary function tests provide the most reliable data, but are limited by measurement variability, the heterogeneity of functional patterns and the confounding effects of non-pulmonary factors. Chest radiography is insensitive to change but may provide rapid confirmation of major disease progression or alert the clinician to respiratory co-morbidities. Although highresolution computed tomography has a central role in assessing disease severity, it should be used very selectively as a monitoring tool due to the associated radiation burden.
\end{abstract}

Ancillary tests include echocardiography and exercise testing to proactively identify cases of pulmonary hypertension and worsening of oxygenation. In summary, a multi-disciplinary approach is essential for the identification of disease progression and prompt treatment of comorbidities that severely impact on the morbidity and mortality of disease.

(c) 2016 S. Karger AG, Basel

\section{Introduction}

Connective tissue diseases (CTDs) compose a heterogeneous group of inflammatory disorders characterised primarily by joint disease and frequently by multi-organ dysfunction including lung involvement. Pulmonary complications, especially interstitial lung disease (ILD), are a frequent cause of morbidity and mortality in pa-

Previous articles in this series: 1. Bouros D, Papiris S, Cottin V: Lung involvement in rheumatic disease: introduction. Respiration 2015;90:1. 2. Papiris SA, Manali ED, Kolilekas L, Kagouridis K, Maniati M, Borie R, Pradere $P$, Crestani B, Bouros D: Investigation of lung involvement in connective tissue disorders. Respiration 2015;90:2-24. 3. Fischer A, Lee JS, Cottin V: Interstitial lung disease evaluation: detecting connective tissue disease. Respiration 2015;90:177-185. 4. Robles-Perez A, Molina-Molina M: Treatment considerations of lung involvement in rheumatologic disease. Respiration 2015;90:265-274.

\section{KARGER}

E-Mail karger@karger.com

www.karger.com/res
(C) 2016 S. Karger AG, Base

0025-7931/16/0912-0089\$39.50/0
Prof. Athol U. Well

Interstitial Lung Disease Unit, Royal Brompton Hospital

Sydney Street

London SW3 6NP (UK)

E-Mail athol.wells@ rbht.nhs.uk 
tients with CTDs. ILD is categorised using the classification system of the idiopathic interstitial pneumonias and is characterised by various inflammatory and fibrotic patterns at lung biopsy and on high-resolution computed tomography (HRCT) scans. ILD is commonly encountered in patients with systemic sclerosis (SSc) and less frequently in rheumatoid arthritis (RA), polymyositis-dermatomyositis (PM/DM), systemic lupus erythematosus (SLE), primary Sjögren syndrome (SS) and mixed CTD (MCTD). Recent advances in the management of these disorders have improved overall outcome in patients with CTDs [1]. With improvements in both survival and the detection of ILD, an increasing number of patients require accurate monitoring of pulmonary complications.

In a large patient sub-group, ILD is subclinical or mild, remains stable and does not require treatment. By contrast, in progressive ILD, aggressive intervention may be needed to prevent increasing respiratory disability and associated mortality. The primary aims in monitoring CTD-ILD are to identify the group of patients that remain stable and do not need treatment, to detect clinically important progression that requires early treatment and to evaluate the efficacy of therapeutic intervention.

Progression of CTD-ILD is defined by subjective and objective variables. Worsening dyspnoea, cough and fatigue may trigger interventions aimed at preventing disabling loss of quality of life. Lung function tests (LFTs) and imaging provide an objective assessment of disease severity, progression and complications. Accurate monitoring requires the multidisciplinary integration of symptoms, functional indices and imaging, with awareness of the major limitations of the evaluation of these domains in isolation. As discussed later, lung complications other than ILD occur frequently in CTDs, and the early detection of supervening ILD is an essential part of monitoring lung involvement and is also covered briefly in this review.

\section{Symptomatic Change in Monitoring}

Worsening respiratory symptoms are often interpreted as indicative of progressive lung disease. However, the interpretation of symptomatic changes can be challenging due to many confounding factors. CTD-associated lung disease is accompanied in most cases by systemic manifestations which influence the interpretation of respiratory symptoms. In idiopathic pulmonary fibrosis (IPF), the most widely studied idiopathic ILD, increasing dyspnoea is a malignant prognostic determinant [2-4]. However, in CTDs, musculoskeletal limitations represent a major confounding factor, and they contribute to the severity of dyspnoea and influence exercise tolerance. In most patients with rheumatologic lung disease, myalgia and arthralgia lead to reduced physical activity and loss of fitness, as well as increasing the work of locomotion. Weight gain due to inactivity or corticosteroid therapy adds to exercise intolerance. Thus, in many patients with CTD and interstitial lung abnormalities, the degree of dyspnoea does not correlate well with the severity of pulmonary fibrosis. The severity of dyspnoea has been quantified in IPF using specific tools such as the Dyspnea-12 [5] and the Medical Research Council Dyspnoea scales [6, 7]. However, these scales, validated at a single point in time and not as measures of serial change, have no current utility in the routine monitoring of CTD-ILD, although recommended as secondary end points in treatment trials [8].

Progressive respiratory symptoms in CTD may also reflect cardiopulmonary processes other than ILD, including pulmonary vascular disease, cardiac disease and infection. Pulmonary vascular disease is a common comorbidity in CTD, and a major cause of mortality especially in patients with SSc [9-11]. Cardiovascular disease is increased in prevalence in patients with CTDs and is associated with ILD [12]. Worsening cough and purulent sputum production are suggestive of acute or sub-acute pulmonary infection, but in patients receiving immunosuppressive therapy, an infection may manifest solely as worsening dyspnoea.

Thus, an inclusive approach is required in the evaluation of worsening dyspnoea, with early recourse to echocardiography and HRCT whenever there is a major increase in exercise intolerance without a concordant change in the severity of ILD. Sub-maximal exercise testing may also have an invaluable role, both at baseline and during monitoring, when the severity of dyspnoea is difficult to rationalise. By reproducing symptoms during a 6-min walk test (6MWT), it is often possible to conclude that dyspnoea is largely ascribable to systemic factors, as shown by the absence of oxygen desaturation when the test is terminated due to exercise intolerance.

In summary, respiratory symptoms are influenced to a great degree by systemic and extra-pulmonary manifestations. Semi-quantitative dyspnoea scales may add value in clinical trials $[8,13,14]$ but offer no practical advantages in routine monitoring. Thus, symptomatic change should not be interpreted in isolation but should be integrated with objective measures, especially LFTs and imaging.

A glossary of abbreviations for routine LFTs is given in table 1.
Paschalaki/Jacob/Wells 
Table 1. Glossary of abbreviations for lung function variables

\begin{tabular}{ll}
\hline DLCO & carbon monoxide diffusing capacity \\
FEV $_{1}$ & forced expiratory volume in $1 \mathrm{~s}$ \\
FVC & forced vital capacity \\
KCO & carbon monoxide transfer coefficient \\
RV & residual volume \\
TLC & total lung capacity \\
VA & alveolar volume \\
\hline
\end{tabular}

\section{Pulmonary Function Tests in Monitoring}

Serial LFTs have a central role in staging the severity and monitoring the progression of rheumatologic lung disease. Lung function variables reflect the histopathologic severity of ILD more accurately than symptoms or chest radiography [15]. Current approaches to lung function monitoring in CTD-ILD have been influenced by IPF studies, in which serial FVC and DLCO decline has been predictive of earlier mortality $[2,16,17]$. The assessment of the prognostic value of LFTs in CTD has been mainly studied in patients with SSc, due to the increased prevalence of associated lung disease in this group of patients. In SSc, DLCO levels $<40 \%$, FVC levels $<60 \%$ and a restrictive $\mathrm{FEV}_{1} / \mathrm{FVC}$ ratio are predictive of a marked increase in mortality $[18,19]$. In SSc, DLCO levels reflect the extent of disease on HRCT more accurately than lung volumes [20]. Thus, the identification of lung function trends that, if not addressed, will result in patients entering the high-risk groups above, is a major monitoring goal. However, there are a number of limitations that need to be taken into account when interpreting the results, as summarised below.

\section{The Meaning of Thresholds for 'Significant' Change}

FVC is highly reproducible. In the absence of confounding processes (major extra-pulmonary restriction due to pleural disease or respiratory muscle weakness), serial decline in FVC is a specific marker of ILD progression, unlike DLCO (which is also influenced by changes due to pulmonary vascular disease). On the basis of reproducibility data, a $10 \%$ decline from baseline in FVC and a $15 \%$ decline in DLCO are both indicative of true change, as opposed to measurement variability. The greater variability in DLCO measurements reflects the fact that DLCO is a calculated variable, computed from measured KCO and measured VA. Changes in LFT variables should be calculated as percentage change from baseline absolute values, rather than from percentages of predicted normal values, which are influenced by changes in patient age during the time interval of monitoring.

However, lung function thresholds are only an approximate guide to disease progression in individual patients. Measurement variation leads equally to the overstatement and under-statement of change; thus, a measured change of $5-10 \%$ in FVC may represent true progression of disease. Furthermore, as discussed later, even when the thresholds are exceeded, causative factors other than ILD progression should be considered, including pulmonary embolism, infection, pulmonary hypertension $(\mathrm{PH})$ and cardiac disease.

\section{Patterns of Lung Function Impairment}

The selection of the LFT variable to be given the most weight in monitoring is complicated by heterogeneity in patterns of lung function impairment, influenced by the nature of the primary underlying pathophysiological process (table 2) and also by the presence of a mixture of pulmonary processes, a frequent scenario in CTD.

Characteristic LFT profiles exist for ILD, pulmonary vascular disease, extra-pulmonary restriction (such as pleural disease and respiratory muscle weakness) and intrinsic airway disease (such as bronchiectasis and bronchiolitis). In pulmonary fibrosis, there is a restrictive ventilatory defect (reduced TLC, increased $\mathrm{FEV}_{1} / \mathrm{FVC}$ ratio) and reduced DLCO, usually $10-20 \%$ lower than lung volumes. In pulmonary vascular disease there is a fall in DLCO disproportionate to lung volumes, best captured by KCO levels (which quantify blood volume per unit volume of ventilated lung). Extra-pulmonary restriction is characterised by a restrictive ventilatory defect, but unlike ILD, the reduction in DLCO is usually minor and KCO levels are often supra-normal. In intrinsic airway disease the ventilatory pattern is obstructive (reduced $\mathrm{FEV}_{1}$ and $\mathrm{FEV}_{1} / \mathrm{FVC}$ ratio, increased TLC) with preservation of DLCO unless there is a significant reduction of $\mathrm{FEV}_{1}$ below 1 litre [21]. The same obstructive pattern is typically found in smoking-related emphysema, but DLCO and KCO levels are significantly reduced [22].

In CTD-ILD, the co-existence of two or more pathologies results in complex patterns of lung function impairment. The most frequent scenarios are coexisting pulmonary fibrosis and pulmonary vascular disease (seen most often in SSc) and coexisting pulmonary fibrosis and emphysema. Serial FVC trends, generally viewed as the most important LFT measure of ILD progression, are confounded by concurrent emphysema (which is 
Table 2. Patterns of pulmonary function impairment associated with the more frequent pulmonary complications of CTD

\begin{tabular}{llll}
\hline & $\begin{array}{l}\text { Pattern of ventilatory } \\
\text { impairment }\end{array}$ & DLCO & Arterial gases at rest \\
\hline Pulmonary fibrosis & Restrictive defect & $\begin{array}{l}\text { Reduced, but KCo levels low } \\
\text { normal or mildly reduced }\end{array}$ & $\begin{array}{l}\text { Hypoxia at rest a feature of } \\
\text { advanced disease }\end{array}$ \\
\hline Pulmonary vascular disease & Normal & $\begin{array}{l}\text { Reduced; DLCO, KCO severely } \\
\text { reduced in PH }\end{array}$ & $\begin{array}{l}\text { Hypoxia at rest often present in } \\
\text { moderate PH }\end{array}$ \\
\hline Bronchiectasis & $\begin{array}{l}\text { Mixed or obstructive } \\
\text { defect }\end{array}$ & Highly variable & $\begin{array}{l}\text { Hypoxia at rest a feature of } \\
\text { end-stage disease }\end{array}$ \\
\hline Extrapulmonary restriction & $\begin{array}{l}\text { Restrictive defect; } \\
\text { reduction in peak flow } \\
\text { may indicate muscle } \\
\text { weakness }\end{array}$ & $\begin{array}{l}\text { DLCO levels low normal or } \\
\text { mildly reduced; KCO levels } \\
\text { supra-normal }\end{array}$ & $\begin{array}{l}\text { In very severe disease, hypercapnic } \\
\text { respiratory failure; alveolar-arterial } \\
\text { oxygen gradient normal }\end{array}$ \\
\hline $\begin{array}{l}\text { Diffuse alveolar haemorrhage } \\
\text { Variable, often mildly } \\
\text { restrictive }\end{array}$ & $\begin{array}{l}\text { DLCO and KCO levels may be } \\
\text { strikingly increased if } \\
\text { haemorrhage is recent }\end{array}$ & $\begin{array}{l}\text { Variable; hypoxia and widening of } \\
\text { alveolar-arterial oxygen gradient } \\
\text { frequent }\end{array}$ \\
\hline
\end{tabular}

Adopted from Wells [75].

associated with relative preservation of FVC levels [23]) or changes in coexisting extra-pulmonary restriction. Therefore, accurate monitoring requires a multidisciplinary approach, in which LFT trends are interpreted with knowledge of the underlying pathophysiological processes and are reconciled with changes in symptoms and imaging.

\section{LFT Trends Do Not Always Represent Changes in ILD Severity}

LFT trends may result from confounding factors such as lower respiratory tract infection, drug-induced pneumonitis, pulmonary vascular disease, cardiac disease, obesity or anaemia. Patients with CTD are susceptible to infection, especially when treated with immunosuppressants, including traditional disease-modifying anti-rheumatic drugs and biological agents (associated with an increased risk of opportunistic infections such as tuberculosis). Systemic manifestations of infection may be attenuated due to immunomodulation, resulting in delayed diagnosis and treatment. Drug-induced pulmonary toxicity should always be considered, and this includes therapies used for CTD (methotrexate, leflunomide, imatinib and rituximab) and a wide variety of other agents used for co-morbidities. Pulmonary vascular disease and cardiac disease may both give rise to selective DLCO trends.

\section{Imaging in Monitoring}

\section{Chest Radiography}

Chest radiography, routinely used in ILD monitoring based on its low cost, ready availability and low radiation dosage, is relatively insensitive in ILD detection [24, 25]. The main value of chest radiography lies in the rapid confirmation of major disease progression in a setting of symptomatic and LFT decline and in the rapid detection of comorbidities such as left heart failure, pneumothorax and pneumonia. However, chest radiography is too insensitive to be integrated into the identification of mildto-moderate ILD progression.

\section{High-Resolution CT}

HRCT is routinely used to detect CTD-ILD, based on its sensitivity (compared to chest radiography, clinical examination and spirometric volumes) and decades of accumulated clinical experience. Reductions in DLCo levels may be as sensitive as HRCT features in CTD-ILD, but they are a non-specific marker of a number of lung pathophysiologic processes.

In CTD patients without evidence of ILD at presentation, serial HRCT might, in principle, be used in surveillance protocols directed towards early detection of supervening ILD. However, enthusiasm for this use of HRCT is muted. Sub-clinical ILD is frequent in CTD, and its early identification often leads to over-treatment. In pri- 

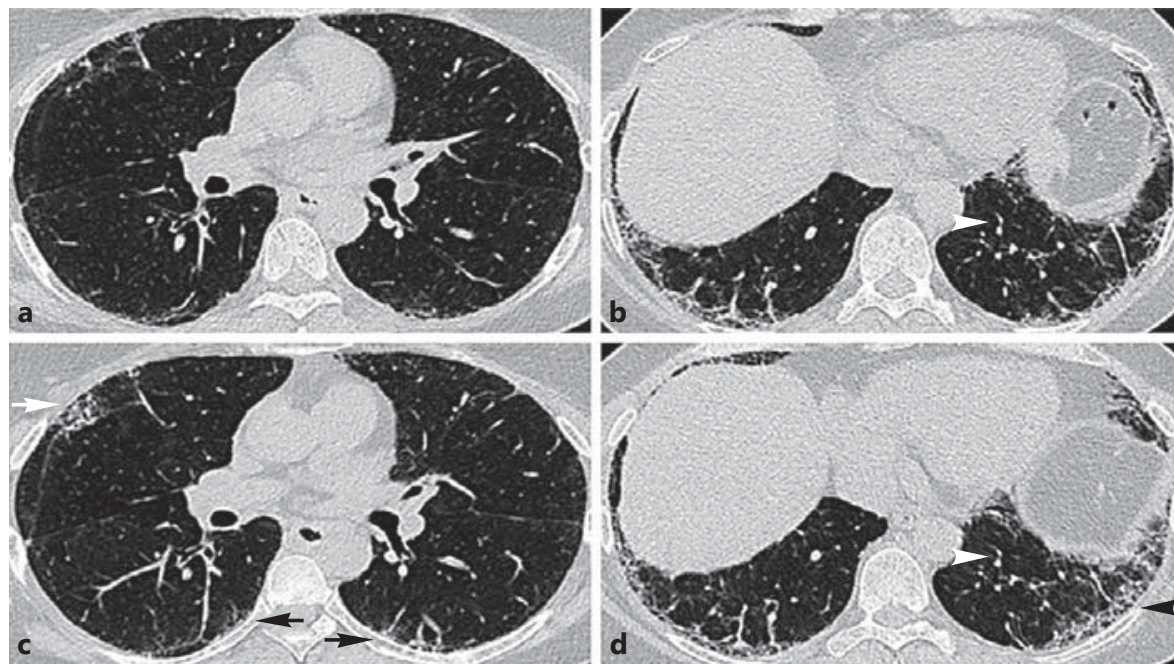

Fig. 1. Assessment of a 54-year-old female diagnosed with limited SSc. a, b Baseline HRCT images of two anatomical levels. c, d HRCT images of the same anatomical levels 9 months later. The patient presented with mild symptoms of dyspnoea on exertion. Her baseline FVC was 81.6 and DLCO 58.1\%. HRCT revealed minor peripheral reticulation in the anterior aspect of the right upper lobe and the dependent regions of both lower lobes $(\mathbf{a}, \mathbf{b})$. Nine months later, she reported minor worsening of exertional dyspnoea, occurring insidiously over months. LFTs showed marginal declines in FVC and DLCO (6 and 9\% change from baseline, respectively). HRCT revealed coarsening of fibrosis in the right upper lobe with an increase in extent (c, arrow). There was an increasing fibrotic change in the lower lobes (c, black arrows; d, black arrowhead) at the same anatomical level, confirmed by a curved vessel (b, d, white arrowheads). Thus, HRCT served to confirm disease progression which was suspected but not definite based on symptoms and serial pulmonary functional change. mary SS, in which the prevalence of clinically significant ILD is low, HRCT abnormalities are present in approximately one third of patients [26]. Similarly, ILD was present on HRCT in $20 \%$ of 150 consecutive outpatients with RA, but was evident on chest radiography in only $2 \%$ [27]. In a large SSc cohort with ILD, the extent of disease on HRCT was very limited $(<10 \%$ of the lung abnormal on HRCT) in a third of cases [28]. To the difficulty of interpreting subtle HRCT abnormalities must be added concerns about excessive radiation especially in younger patients with CTD - and, in RA, the likelihood that protocoled HRCT surveillance will lead to a need for additional intensive HRCT monitoring of rheumatoid nodules. Thus, the current consensus is that in patients with no evidence of ILD, follow-up HRCT should be performed only in selected cases, to clarify uncertainties related to symptomatic or pulmonary function trends.

The same reservations apply to routine HRCT monitoring in established CTD-ILD, especially with regard to the radiation burden and the difficulty of interpreting subtle morphologic change, associated with symptomatic and pulmonary function stability. Therefore, serial HRCT should be used (a) to resolve discordances between symp- tomatic and pulmonary function trends, (b) to clarify symptomatic and marginal pulmonary function decline suggestive of but not diagnostic for disease progression (fig. 1) and (c) to identify ILD progression when pathologies co-exist [e.g. ILD and pulmonary vascular disease in SSc (fig. 2), ILD and respiratory muscle weakness in inflammatory myopathy]. This principle applies equally to the distinction between progressive ILD and other causes of rapid decline, including bacterial or opportunistic infection, drug-induced pneumonitis, heart failure or pulmonary thromboembolism. In addition, HRCT may be useful when malignancy is suspected.

\section{Lung Ultrasound}

Lung ultrasound shows some promise as a radiationfree method of screening for the development of supervening ILD in CTD based on the identification of 'B-lines', vertical artefacts arising from the pleural space representing the sonographic sign of interstitial lung involvement $[29,30]$. Lung ultrasound is inexpensive, widely available, reproducible and easily performed at the bedside, in combination with echocardiography $[31,32]$. When examined against lung HRCT, lung ultrasound has a high sensitivity 
Fig. 2. Assessment of a 45-year-old female diagnosed with diffuse SSc. a, b Baseline HRCT images of two anatomical levels. c, d HRCT images of the same anatomical levels 7 months later. The patient presented with symptoms of cough and dyspnoea on mild exertion. Her baseline FVC was 58.8 and DLCO $34.3 \%$. HRCT revealed reticulation and traction bronchiectasis within the left lower lobe indicative of fibrosis. Fibrosis was also demonstrated to a lesser extent within the lingula (a, b). Seven months later she reported worsening exertional dyspnoea. LFTs showed an isolated serial decline in DLCO (a 20\% decline from baseline, associated with a $2.5 \%$ rise in $\mathrm{FVC}$ ), raising the possibility that the symptomatic decline resulted from progressive pulmonary vasculopathy rather than increasing pulmonary fibrosis. However, on HRCT, images acquired at the same anatomical level (confirmed by the vessel above the asterisk) showed definitively that fibrosis had worsened in extent, particularly within the lingula (c, arrow). More basally, a region of spared lung (b, d, small ' $\mathrm{x}$ ') had decreased in size on the subsequent CT as peripheral fibrosis increased in extent (d, arrowhead). Fibrosis within the lingula was also increased in extent and severity (d, arrow). Thus, HRCT served to confirm progression of pulmonary fibrosis as the cause of clinical deterioration.
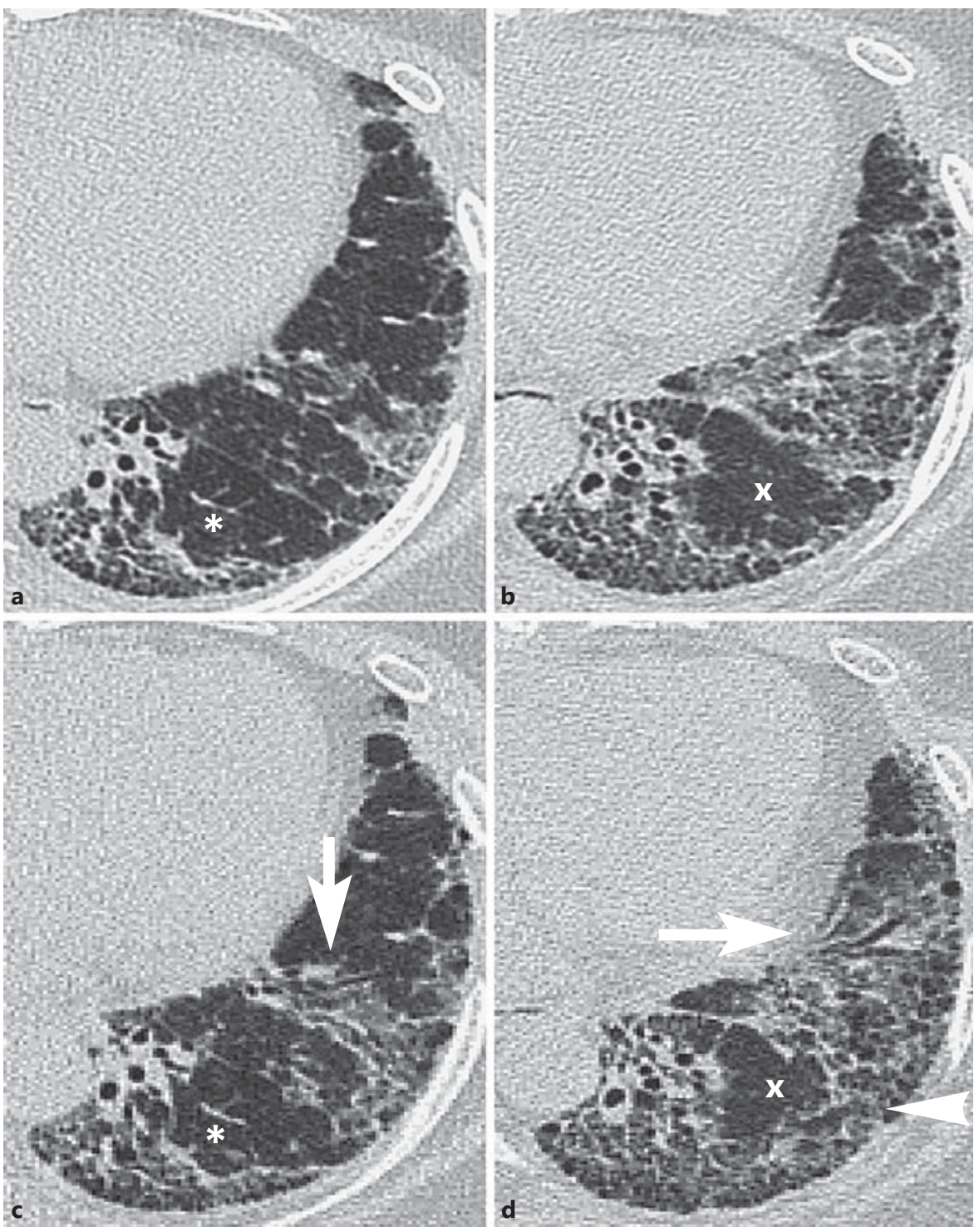

and negative predictive value for ILD [31-33], but it has yet to be validated in the monitoring of ILD progression and has no routine clinical role in the outpatient clinic.

\section{Pulmonary ‘Disease Activity' in Monitoring}

The term 'disease activity' has caused great confusion in ILD, since it is applied equally to the presence of reversible disease and to the risk of disease progression when disease is irreversible. However, the unifying factor is the unmet need for a reliable means of predicting future disease behaviour, both in treated and untreated patients.
Biomarkers of various kinds have an important theoretical role in this regard, both in initial evaluation and in monitoring. However, candidate serum, bronchoalveolar lavage and imaging biomarkers in CTD-ILD have mostly been studied only at a single point in time [34], including surfactant protein A and B (SP-A, SP-B) [35-37], Krebs von den Lungen (KL)-6 [35, 38-41], other lung epithelium-derived proteins, as well as chemokines, cytokines, matrix metalloproteinases and interleukins [34, 42-48]. Serial biomarker trends have the potential to refine prognostic evaluation with exciting possibilities with the introduction of a therapy, and short-term biomarker changes might provide invaluable information on longer-term 
efficacy. However, studies of this sort require certain knowledge of trend thresholds indicative of true change, as opposed to spurious change due to measurement variation. Currently, data on the day-to-day reproducibility of serum biomarker levels - in CTD-ILD and, indeed, in ILD in general - are seriously under-studied.

The exception with regard to use in serial monitoring is fluoro-2-deoxy-D-glucose positron emission tomography/ computed tomography (FDG PET/CT) scanning. In both sarcoidosis [49-51] and CTD [52, 53], FDG PET/CT activity reflects the level of pulmonary inflammation, with reductions in abnormal pulmonary signals observed with treatment. However, FDG PET/CT is expensive and often not readily available, and abnormal signals are non-specific, occurring also in drug-induced lung injury, infection and cancer. Further prospective studies are required to validate the use of serial FDG PET/CT in monitoring CTD-ILD.

Specific autoantibodies have no established role in serial CTD monitoring. However, knowledge of the autoantibody status undoubtedly serves to inform clinicians as to the likely importance of pulmonary monitoring, based on lower or higher likelihoods of supervening ILD. Patients with SSc and anti-topoisomerase I antibodies (also known as anti-scleroderma-70 antibodies) are more likely to develop diffuse cutaneous disease and significant lung fibrosis [54]. Anti-topoisomerase I antibody titres have been correlated with disease activity and severity $[55,56]$. In contrast, anti-centromere antibodies are associated with limited cutaneous disease and increased risk of PH [19, 57]. In RA, rheumatoid factor and anti-citrullinated protein antibodies have been associated with ILD [58-60]. In PM/DM, anti-Jo- 1 and anti-SSA/Ro antibodies have also been found to be linked with severe and extensive ILD [61]. In MCTD, anti-Ro52 have been associated with lung fibrosis [62].

\section{PH in Monitoring}

$\mathrm{PH}$ is increased in prevalence in CTDs, especially in SSc, SLE, MCTD and to a lesser extent in RA, SS and PM/ $\mathrm{DM}$ [63-66]. $\mathrm{PH}$ is a malignant prognostic determinant, and for this reason alone, irrespective of treatment considerations, the identification of $\mathrm{PH}$ is an important part of routine monitoring. Particularly in SLE and MCTD, early diagnosis of $\mathrm{PH}$ is of significant importance, as it can be responsive to treatment [67]. Right heart catheterisation is the reference standard in $\mathrm{PH}$ for the diagnosis, the definition of severity and the exclusion of left-sided heart disease [68] but is invasive and needs to be reserved for patients in whom $\mathrm{PH}$ is at least moderately probable. Pulmonary function profiles suggestive of supervening pulmonary vasculopathy include a disproportionate reduction in DLCO [69], reduced KCO [20] or increased FVC/DLCO ratio $[70,71]$, severe resting hypoxia and arterial oxygen desaturation with minor exertion. The current European Society of Cardiology (ESC)/European Respiratory Society (ERS) guidelines recommend echocardiography in all CTD patients with pulmonary symptoms [68].

In SSc, resting echocardiography is recommended as a screening test in asymptomatic patients, followed by annual screening with echocardiography, DLCO and biomarkers, including N-terminal pro-brain natriuretic peptide (NT-proBNP) [63, 68], but this 'one-size-fits-all' approach is not accepted by many clinicians. The recently published multicentre DETECT study [72] validated an algorithm in which 6 non-echocardiographic variables (FVC or DLCO, present/past telangiectasia, anti-centromere antibodies, NT-proBNP, serum urate and right axis deviation on the electrocardiogram) are used to determine the need for echocardiographic evaluation, which is then used to ascertain whether right heart catheterisation is required [72].

Based on these considerations, serial LFTs with gas transfer estimation are an essential part of the routine monitoring of both CTD-ILD and CTD patients at risk of developing $\mathrm{PH}$, based on baseline serological data. In reality, the evaluation of the likelihood of $\mathrm{PH}$ requires the integration of a number of markers, including KCO or FVC/DLCO levels, resting oxygen levels, 6MWT data, serum NT-proBNP levels, enlargement of the pulmonary artery on HRCT and echocardiography. It is intuitively correct to evaluate serial trends in these markers during monitoring, but as is often the case in complex disease, there is a credibility gap between what is recommended in evidence-based guidelines and what makes sense to the experienced clinician. More work is needed on serial trends in PH markers in this crucial aspect of monitoring.

\section{Oxygen Desaturation in Monitoring}

As in idiopathic interstitial pneumonias, patients with CTD-ILD should be monitored by pulse oximetry for oxygen desaturation at rest and with exertion to confirm the adequacy of oxygenation and identify the patients in need of oxygen supplementation [73]. Particular attention is required in some patients with poor circulation when monitoring oxygen by pulse oximetry. In general, desaturation below $88 \%$ with exercise (or with a $6 \mathrm{MWT}$ ) indicates a need for oxygen supplementation [74] and alerts the clinician to the possibility of $\mathrm{PH}$. However, $6 \mathrm{MWT}$ 
data are also influenced by musculoskeletal factors, pulmonary vasculopathy and cardiac involvement, often complicating clinical interpretation.

\section{Frequency of Monitoring}

During early disease, it is usual to re-evaluate patients with CTD-ILD at 3- to 4-monthly intervals. This is particularly important in patients with SSc, as the greatest risk of progression occurs during the first 4 years of systemic disease [19]. If pulmonary disease is seen to be stable during the first year, with or without treatment, the time interval between assessments can be gradually increased. However, even in mild stable pulmonary disease, long-term annual monitoring is appropriate.

When higher-dose therapies are introduced in the hope of reversing disease, it is common practice to assess responsiveness at 4-6 weeks and to tailor further monitoring to the treatment plan and initial responsiveness. When there is severe disease and further progression would be likely to lead to disability, more frequent monitoring is appropriate than in patients with a good pulmonary reserve. In general, the severity of disease should be re-evaluated no longer than 3-4 months after any changes in treatment, with the patient advised that early evaluation might be required in the event of worsening symptoms.

\section{Conclusions}

Monitoring of rheumatologic lung disease cannot be based on a single test but requires the integration of many variables including changes in symptoms, chest radiography and pulmonary function tests. Ancillary tests include HRCT, serum and bronchoalveolar lavage biomarkers, echocardiography and exercise testing in selected patients.

Symptomatic changes, even though of significant importance, should not be used in isolation for disease monitoring but in combination with objective and more specific variables, using pulmonary function tests and imaging. Pulmonary function tests provide the most reliable data, but several limitations should be taken into account, such as measurement variability, heterogeneity of pulmonary function patterns and confounding effects of nonpulmonary factors. Even though chest radiography is insensitive, it retains a useful monitoring role. HRCT has a central role in assessing disease severity, but it should be used selectively for monitoring due to the associated radiation burden. A proactive approach should be taken to identify cases of PH early. In summary, a multi-disciplinary approach is essential for the monitoring of CTDrelated lung disease and for the identification and early treatment of comorbidities that severely impact the morbidity and mortality of the disease.

\section{References}

1 Nihtyanova SI, Schreiber BE, Ong VH, Rosenberg D, Moinzadeh P, Coghlan JG, Wells AU, Denton CP: Prediction of pulmonary complications and long-term survival in systemic sclerosis. Arthritis Rheumatol 2014; 66:1625-1635.

-2 Collard HR, King TE Jr, Bartelson BB, Vourlekis JS, Schwarz MI, Brown KK: Changes in clinical and physiologic variables predict survival in idiopathic pulmonary fibrosis. Am J Respir Crit Care Med 2003;168:538-542.

-3 American Thoracic Society/European Respiratory Society International Multidisciplinary Consensus Classification of the Idiopathic Interstitial Pneumonias. This joint statement of the American Thoracic Society (ATS), and the European Respiratory Society (ERS) was adopted by the ATS board of directors, June 2001 and by the ERS Executive Committee, June 2001. Am J Respir Crit Care Med 2002; 165:277-304.

-4 Martinez FJ, Safrin S, Weycker D, Starko KM, Bradford WZ, King TE Jr, Flaherty KR, Schwartz DA, Noble PW, Raghu G, Brown KK: The clinical course of patients with idio- pathic pulmonary fibrosis. Ann Intern Med 2005;142:963-967.

5 Yorke J, Swigris J, Russell AM, Moosavi SH, Ng Man Kwong G, Longshaw M, Jones PW: Dyspnea-12 is a valid and reliable measure of breathlessness in patients with interstitial lung disease. Chest 2011;139:159-164.

-6 Manali ED, Lyberopoulos P, Triantafillidou C, Kolilekas LF, Sotiropoulou C, Milic-Emili J, Roussos C, Papiris SA: MRC chronic Dyspnea Scale: relationships with cardiopulmonary exercise testing and 6-minute walk test in idiopathic pulmonary fibrosis patients: a prospective study. BMC Pulm Med 2010;10: 32.

7 Nishiyama O, Taniguchi $\mathrm{H}$, Kondoh $\mathrm{Y}$, Kimura T, Kato K, Kataoka K, Ogawa T, Watanabe F, Arizono S: A simple assessment of dyspnoea as a prognostic indicator in idiopathic pulmonary fibrosis. Eur Respir J 2010; 36:1067-1072.

8 Saketkoo LA, Mittoo S, Huscher D, Khanna D, Dellaripa PF, Distler O, Flaherty KR, Frankel S, Oddis CV, Denton CP, et al: Connective tissue disease related interstitial lung diseases and idiopathic pulmonary fibrosis: provisional core sets of domains and instruments for use in clinical trials. Thorax 2014;69:428436.

9 Chung L, Liu J, Parsons L, Hassoun PM, McGoon M, Badesch DB, Miller DP, Nicolls MR, Zamanian RT: Characterization of connective tissue disease-associated pulmonary arterial hypertension from REVEAL: identifying systemic sclerosis as a unique phenotype. Chest 2010;138:1383-1394.

10 Condliffe R, Kiely DG, Peacock AJ, Corris PA, Gibbs JS, Vrapi F, Das C, Elliot CA, Johnson $\mathrm{M}$, DeSoyza J, et al: Connective tissue diseaseassociated pulmonary arterial hypertension in the modern treatment era. Am J Respir Crit Care Med 2009;179:151-157.

11 Condliffe R, Howard LS: Connective tissue disease-associated pulmonary arterial hypertension. F1000Prime Rep 2015;7:06.

12 Wang X, Lou M, Li Y, Ye W, Zhang Z, Jia X, Shi H, Zhu X, Wang L: Cardiovascular involvement in connective tissue disease: the role of interstitial lung disease. PLoS One 2015;10:e0121976. 
-13 Saketkoo LA, Mittoo S, Frankel S, LeSage D, Sarver C, Phillips K, Strand V, Matteson EL: Reconciling healthcare professional and patient perspectives in the development of disease activity and response criteria in connective tissue disease-related interstitial lung diseases. J Rheumatol 2014;41:792-798.

14 Khanna D, Mittoo S, Aggarwal R, Proudman SM, Dalbeth N, Matteson EL, Brown K, Flaherty K, Wells AU, Seibold JR, Strand V: Connective tissue disease-associated interstitial lung diseases (CTD-ILD) - report from OMERACT CTD-ILD Working Group. J Rheumatol 2015;42:2168-2171.

15 Keogh BA, Crystal RG: Clinical significance of pulmonary function tests. Pulmonary function testing in interstitial pulmonary disease. What does it tell us? Chest 1980;78:856865.

16 Latsi PI, du Bois RM, Nicholson AG, Colby TV, Bisirtzoglou D, Nikolakopoulou A, Veeraraghavan S, Hansell DM, Wells AU: Fibrotic idiopathic interstitial pneumonia: the prognostic value of longitudinal functional trends. Am J Respir Crit Care Med 2003;168:531537.

-17 Flaherty KR, Mumford JA, Murray S, Kazerooni EA, Gross BH, Colby TV, Travis WD, Flint A, Toews GB, Lynch JP 3rd, Martinez FJ: Prognostic implications of physiologic and radiographic changes in idiopathic interstitial pneumonia. Am J Respir Crit Care Med 2003; 168:543-548.

18 Morgan C, Knight C, Lunt M, Black CM, Silman AJ: Predictors of end stage lung disease in a cohort of patients with scleroderma. Ann Rheum Dis 2003;62:146-150.

-19 Steen VD, Conte C, Owens GR, Medsger TA Jr: Severe restrictive lung disease in systemic sclerosis. Arthritis Rheum 1994;37:12831289.

20 Wells AU, Hansell DM, Rubens MB, King $\mathrm{AD}$, Cramer D, Black CM, du Bois RM: Fibrosing alveolitis in systemic sclerosis: indices of lung function in relation to extent of disease on computed tomography. Arthritis Rheum 1997;40:1229-1236.

-21 Hansell DM, Rubens MB, Padley SP, Wells AU: Obliterative bronchiolitis: individual CT signs of small airways disease and functional correlation. Radiology 1997;203:721-726.

-22 Gould GA, Redpath AT, Ryan M, Warren PM, Best JJ, Flenley DC, MacNee W: Lung CT density correlates with measurements of airflow limitation and the diffusing capacity. Eur Respir J 1991;4:141-146.

$\checkmark 23$ Wells AU, Desai SR, Rubens MB, Goh NS, Cramer D, Nicholson AG, Colby TV, du Bois RM, Hansell DM: Idiopathic pulmonary fibrosis: a composite physiologic index derived from disease extent observed by computed tomography. Am J Respir Crit Care Med 2003; 167:962-969.

-24 Schurawitzki H, Stiglbauer R, Graninger W, Herold C, Pölzleitner D, Burghuber OC, Tscholakoff D: Interstitial lung disease in progressive systemic sclerosis: high-resolution
CT versus radiography. Radiology 1990;176: 755-759.

25 Epler GR, McLoud TC, Gaensler EA, Mikus JP, Carrington CB: Normal chest roentgenograms in chronic diffuse infiltrative lung disease. N Engl J Med 1978;298:934-939.

-26 Franquet T, Gimenez A, Monill JM, Diaz C, Geli C: Primary Sjögren's syndrome and associated lung disease: CT findings in 50 patients. AJR Am J Roentgenol 1997;169:655-658.

27 Dawson JK, Fewins HE, Desmond J, Lynch MP, Graham DR: Fibrosing alveolitis in patients with rheumatoid arthritis as assessed by high resolution computed tomography, chest radiography, and pulmonary function tests. Thorax 2001;56:622-627.

28 Goh NS, Desai SR, Veeraraghavan S, Hansell DM, Copley SJ, Maher TM, Corte TJ, Sander CR, Ratoff J, Devaraj A, et al: Interstitial lung disease in systemic sclerosis: a simple staging system. Am J Respir Crit Care Med 2008;177: 1248-1254.

29 Lichtenstein DA: Ultrasound in the management of thoracic disease. Crit Care Med 2007; 35:S250-S261.

-30 Sperandeo M, Varriale A, Sperandeo G, Filabozzi P, Piattelli ML, Carnevale V, Decuzzi M, Vendemiale G: Transthoracic ultrasound in the evaluation of pulmonary fibrosis: our experience. Ultrasound Med Biol 2009;35:723-729.

- 31 Barskova T, Gargani L, Guiducci S, Randone SB, Bruni C, Carnesecchi G, Conforti ML, Porta F, Pignone A, Caramella D, et al: Lung ultrasound for the screening of interstitial lung disease in very early systemic sclerosis. Ann Rheum Dis 2013;72:390-395.

32 Delle Sedie A, Carli L, Cioffi E, Bombardieri $S$, Riente L: The promising role of lung ultrasound in systemic sclerosis. Clin Rheumatol 2012;31:1537-1541.

33 Cogliati C, Antivalle M, Torzillo D, Birocchi S, Norsa A, Bianco R, Costantino G, Ditto MC, Battellino M, Sarzi Puttini PC, Montano $\mathrm{N}$ : Standard and pocket-size lung ultrasound devices can detect interstitial lung disease in rheumatoid arthritis patients. Rheumatology (Oxford) 2014;53:1497-1503.

34 Bonella F, Costabel U: Biomarkers in connective tissue disease-associated interstitial lung disease. Semin Respir Crit Care Med 2014;35: 181-200.

35 Bonella F, Volpe A, Caramaschi P, Nava C, Ferrari P, Schenk K, Ohshimo S, Costabel U, Ferrari M: Surfactant protein D and KL-6 serum levels in systemic sclerosis: correlation with lung and systemic involvement. Sarcoidosis Vasc Diffuse Lung Dis 2011;28:27-33.

36 Takahashi H, Kuroki Y, Tanaka H, Saito T, Kurokawa K, Chiba H, Sagawa A, Nagae H, Abe S: Serum levels of surfactant proteins A and $\mathrm{D}$ are useful biomarkers for interstitial lung disease in patients with progressive systemic sclerosis. Am J Respir Crit Care Med 2000;162:258-263.

37 Asano Y, Ihn H, Yamane K, Yazawa N, Kubo M, Fujimoto M, Tamaki K: Clinical signifi- cance of surfactant protein D as a serum marker for evaluating pulmonary fibrosis in patients with systemic sclerosis. Arthritis Rheum 2001;44:1363-1369.

38 Yamane K, Ihn H, Kubo M, Yazawa N, Kikuchi K, Soma Y, Tamaki K: Serum levels of KL-6 as a useful marker for evaluating pulmonary fibrosis in patients with systemic sclerosis. J Rheumatol 2000;27:930-934.

39 Yanaba K, Hasegawa M, Hamaguchi Y, Fujimoto M, Takehara K, Sato S: Longitudinal analysis of serum KL-6 levels in patients with systemic sclerosis: association with the activity of pulmonary fibrosis. Clin Exp Rheumatol 2003;21:429-436.

40 Kinoshita F, Hamano H, Harada H, Kinoshita $T$, Igishi $T$, Hagino $H$, Ogawa T: Role of KL-6 in evaluating the disease severity of rheumatoid lung disease: comparison with HRCT. Respir Med 2004;98:1131-1137.

-41 Nakajima H, Harigai M, Hara M, Hakoda M Tokuda H, Sakai F, Kamatani N, Kashiwazaki S: KL-6 as a novel serum marker for interstitial pneumonia associated with collagen diseases. J Rheumatol 2000;27:1164-1170.

42 De Lauretis A, Sestini P, Pantelidis P, Hoyles R, Hansell DM, Goh NS, Zappala CJ, Visca D, Maher TM, Denton CP, et al: Serum interleukin 6 is predictive of early functional decline and mortality in interstitial lung disease associated with systemic sclerosis. J Rheumatol 2013;40:435-446.

43 De Lauretis A, Renzoni EA: Molecular biomarkers in interstitial lung diseases. Mol Diagn Ther 2014;18:505-522.

44 Nordenbaek C, Johansen JS, Halberg P, Wiik A, Garbarsch C, Ullman S, Price PA, Jacobsen S: High serum levels of YKL-40 in patients with systemic sclerosis are associated with pulmonary involvement. Scand J Rheumatol 2005;34:293-297.

45 Prasse A, Pechkovsky DV, Toews GB, Schäfer M, Eggeling S, Ludwig C, Germann M, Kollert F, Zissel G, Müller-Quernheim J: CCL18 as an indicator of pulmonary fibrotic activity in idiopathic interstitial pneumonias and systemic sclerosis. Arthritis Rheum 2007:56:1685-1693.

$\checkmark 46$ Tiev KP, Hua-Huy T, Kettaneh A, Gain M, Duong-Quy S, Toledano C, Cabane J, DinhXuan AT: Serum CC chemokine ligand- 18 predicts lung disease worsening in systemic sclerosis. Eur Respir J 2011;38:1355-1360.

47 Schmidt K, Martinez-Gamboa L, Meier S, Witt C, Meisel C, Hanitsch LG, Becker MO, Huscher D, Burmester GR, Riemekasten G: Bronchoalveoloar [sic!] lavage fluid cytokines and chemokines as markers and predictors for the outcome of interstitial lung disease in systemic sclerosis patients. Arthritis Res Ther 2009;11:R111.

48 Andersen GN, Nilsson K, Pourazar J, Hackett TL, Kazzam E, Blomberg A, Waldenström A, Warner J, Rantapää-Dahlqvist S, MinchevaNilsson L, Sandström T: Bronchoalveolar matrix metalloproteinase 9 relates to restrictive lung function impairment in systemic sclerosis. Respir Med 2007;101:2199-2206.
Monitoring of Lung Involvement in Rheumatologic Disease 
49 Teirstein AS, Machac J, Almeida O, Lu P, Padilla ML, Iannuzzi MC: Results of 188 wholebody fluorodeoxyglucose positron emission tomography scans in 137 patients with sarcoidosis. Chest 2007;132:1949-1953.

-50 Nishiyama Y, Yamamoto Y, Fukunaga K, Takinami H, Iwado Y, Satoh K, Ohkawa M: Comparative evaluation of ${ }^{18} \mathrm{~F}$-FDG PET and ${ }^{67} \mathrm{Ga}$ scintigraphy in patients with sarcoidosis. J Nucl Med 2006;47:1571-1576.

- 51 Braun JJ, Kessler R, Constantinesco A, Imperiale $\mathrm{A}:{ }^{18} \mathrm{~F}$-FDG PET/CT in sarcoidosis management: review and report of 20 cases. Eur J Nucl Med Mol Imaging 2008;35:1537-1543.

-52 Uehara T, Takeno M, Hama M, Yoshimi R, Suda A, Ihata A, Ueda A, Tateishi U, Ishigatsubo Y: Deep-inspiration breath-hold ${ }^{18} \mathrm{~F}$ FDG-PET/CT is useful for assessment of connective tissue disease associated interstitial pneumonia. Mod Rheumatol 2015, Epub ahead of print.

-53 Cohen C, Mekinian A, Uzunhan Y, Fauchais AL, Dhote R, Pop G, Eder V, Nunes H, Brillet PY, Valeyre D, et al: ${ }^{18} \mathrm{~F}$-fluorodeoxyglucose positron emission tomography/computer tomography as an objective tool for assessing disease activity in Sjögren's syndrome. Autoimmun Rev 2013;12:1109-1114.

54 Briggs DC, Vaughan RW, Welsh KI, Myers A, duBois RM, Black CM: Immunogenetic prediction of pulmonary fibrosis in systemic sclerosis. Lancet 1991;338:661-662.

-55 Kuwana M, Kaburaki J, Mimori T, Kawakami Y, Tojo T: Longitudinal analysis of autoantibody response to topoisomerase I in systemic sclerosis. Arthritis Rheum 2000;43:10741084.

-56 Hu PQ, Fertig N, Medsger TA Jr, Wright TM: Correlation of serum anti-DNA topoisomerase I antibody levels with disease severity and activity in systemic sclerosis. Arthritis Rheum 2003;48:1363-1373.

57 Reveille JD, Solomon DH: Evidence-based guidelines for the use of immunologic tests: anticentromere, Scl-70, and nucleolar antibodies. Arthritis Rheum 2003;49:399-412.

- 58 Mori S, Koga Y, Sugimoto M: Different risk factors between interstitial lung disease and airway disease in rheumatoid arthritis. Respir Med 2012;106:1591-1599.
59 Aubart F, Crestani B, Nicaise-Roland P, Tubach F, Bollet C, Dawidowicz K, Quintin E, Hayem G, Palazzo E, Meyer O, et al: High levels of anti-cyclic citrullinated peptide autoantibodies are associated with co-occurrence of pulmonary diseases with rheumatoid arthritis. J Rheumatol 2011;38:979-982.

60 Alexiou I, Germenis A, Koutroumpas A, Kontogianni A, Theodoridou K, Sakkas LI: Anti-cyclic citrullinated peptide-2 (CCP2) autoantibodies and extra-articular manifestations in Greek patients with rheumatoid arthritis. Clin Rheumatol 2008;27:511-513.

61 La Corte R, Lo Mo Naco A, Locaputo A, Dolzani F, Trotta F: In patients with antisynthetase syndrome the occurrence of anti-Ro/SSA antibodies causes a more severe interstitial lung disease. Autoimmunity 2006;39:249253.

62 Gunnarsson R, El-Hage F, Aaløkken TM, Reiseter S, Lund MB, Garen T, Molberg Ø: Associations between anti-Ro52 antibodies and lung fibrosis in mixed connective tissue disease. Rheumatology (Oxford) 2015, Epub ahead of print.

63 Khanna D, Gladue H, Channick R, Chung L, Distler O, Furst DE, Hachulla E, Humbert M, Langleben D, Mathai SC, et al: Recommendations for screening and detection of connective tissue disease-associated pulmonary arterial hypertension. Arthritis Rheum 2013;65: 3194-3201.

64 Gashouta MA, Humbert M, Hassoun PM: Update in systemic sclerosis-associated pulmonary arterial hypertension. Presse Med 2014; 43:e293-e304.

65 Hajas A, Szodoray P, Nakken B, Gaal J, Zöld E, Laczik R, Demeter N, Nagy G, Szekanecz Z, Zeher M, et al: Clinical course, prognosis, and causes of death in mixed connective tissue disease. J Rheumatol 2013;40:1134-1142.

66 Wigley FM, Lima JA, Mayes M, McLain D, Chapin JL, Ward-Able C: The prevalence of undiagnosed pulmonary arterial hypertension in subjects with connective tissue disease at the secondary health care level of community-based rheumatologists (the UNCOVER study). Arthritis Rheum 2005;52:2125-2132.

67 Sanchez O, Sitbon O, Jaïs X, Simonneau G, Humbert M: Immunosuppressive therapy in connective tissue diseases-associated pulmonary arterial hypertension. Chest 2006;130: 182-189.
68 Galiè N, Humbert M, Vachiery JL, Gibbs S, Lang I, Torbicki A, Simonneau G, Peacock A, Vonk Noordegraaf A, Beghetti M, et al: 2015 ESC/ERS Guidelines for the diagnosis and treatment of pulmonary hypertension: the Joint Task Force for the Diagnosis and Treatment of Pulmonary Hypertension of the European Society of Cardiology (ESC) and the European Respiratory Society (ERS): endorsed by: Association for European Paediatric and Congenital Cardiology (AEPC), International Society for Heart and Lung Transplantation (ISHLT). Eur Respir J 2015;46: 903-975.

69 Burke CM, Glanville AR, Morris AJ, Rubin D, Harvey JA, Theodore J, Robin ED: Pulmonary function in advanced pulmonary hypertension. Thorax 1987;42:131-135.

70 Nathan SD, Shlobin OA, Ahmad S, Urbanek S, Barnett SD: Pulmonary hypertension and pulmonary function testing in idiopathic pulmonary fibrosis. Chest 2007;131:657-663.

71 Steen VD, Graham G, Conte C, Owens G, Medsger TA Jr: Isolated diffusing capacity reduction in systemic sclerosis. Arthritis Rheum 1992;35:765-770.

72 Coghlan JG, Denton CP, Grünig E, Bonderman D, Distler O, Khanna D, Müller-Ladner U, Pope JE, Vonk MC, Doelberg M, et al: Evidence-based detection of pulmonary arterial hypertension in systemic sclerosis: the DETECT study. Ann Rheum Dis 2014;73: 1340-1349.

73 Raghu G, Collard HR, Egan JJ, Martinez FJ, Behr J, Brown KK, Colby TV, Cordier JF, Flaherty KR, Lasky JA, et al: An official ATS/ ERS/JRS/ALAT statement: idiopathic pulmonary fibrosis: evidence-based guidelines for diagnosis and management. Am J Respir Crit Care Med 2011;183:788-824.

74 ATS statement: guidelines for the six-minute walk test. Am J Respir Crit Care Med 2002; 166:111-117.

75 Wells AU: Pulmonary function tests in connective tissue disease. Semin Respir Crit Care Med 2007;28:379-388. 